\title{
Feasibility of the Positive Thoughts and Actions Prevention Program for Middle Schoolers at Risk for Depression
}

\author{
Carolyn A. McCarty, ${ }^{1}$ Heather D. Violette, ${ }^{1}$ and Elizabeth McCauley $^{2}$ \\ ${ }^{1}$ Seattle Children's Hospital and University of Washington, Center for Child Health, Behavior, and Development, \\ 1100 Olive Way, Suite 500, MS MPW 8-1 Seattle, WA 98101, USA \\ ${ }^{2}$ Seattle Children's Hospital, 4800 Sand Point Way NE, MS W-3636, Seattle, WA 98105, USA
}

Correspondence should be addressed to Carolyn A. McCarty, cari.mccarty@seattlechildrens.org

Received 13 May 2010; Revised 24 July 2010; Accepted 24 July 2010

Academic Editor: Bettina F. Piko

Copyright ( 92011 Carolyn A. McCarty et al. This is an open access article distributed under the Creative Commons Attribution License, which permits unrestricted use, distribution, and reproduction in any medium, provided the original work is properly cited.

Despite the importance of adolescent depression, few school-based prevention programs have been developed and tested in the United States with middle school populations. This study examined the acceptability and changes in targeted outcomes for a new preventative program, Positive Thoughts and Actions (PTA). Sixty-seven 7th grade students with elevated depressive symptoms were recruited from public schools and randomized to the 12-week PTA program with a parent-component or to a school-as-usual control group. The PTA prevention program was well received by students and parents, yielding high rates of participation and satisfaction among those randomized to receive the intervention. However, analyses of the efficacy of the program in changing depressive symptoms were not significant. In terms of our proximal program targets, most differences were not statistically significant, though effect sizes suggested advantage of PTA over control group in coping, cognitive style, and parentchild communication. This preliminary research highlights a need for further testing of programs for school-based prevention of depression and promotion of positive emotional health.

\section{Introduction}

Elevated levels of depressive symptoms can be detrimental for adolescents because they may interfere with important developmental processes and lead to a cascade of adjustment difficulties [1]. Youth with depressive symptoms are at significant risk for meeting diagnostic criteria for a depressive disorder later in adolescence [2] and in adulthood [3]. Depression and depressive symptoms are a primary risk for suicide, a leading cause of death for adolescents [4]. Longitudinal research has shown substantial continuity of youth depression into adulthood, with impaired functioning in work, social, and family life, and elevated risk of adult suicide attempts and completed suicide $[5,6]$. A recent report by the National Research Council and the Institute of Medicine concludes that it is critical to shift the focus to advancing health and preventing disorders from occurring in the first place, rather than waiting until a disorder is well established and has done considerable harm [7]. The goal of the current paper is to describe the development of a prevention model that addresses the needs of middle/junior high school students at risk for depression.

Schools play an increasingly important role in providing mental health services to children [8]. For the majority of children and adolescents, the school system provides the only source of mental health service [9]. Despite the importance of addressing depression and mental health as an overall component of youth health, only a handful of preventative programs targeting depression have been developed for middle schools, most of which have been tested in Australia [10-12]. In this country, the Penn Resiliency Program and the Coping and Support Training Program are the only two preventative interventions targeting depression that have been specifically developed for and empirically tested in middle/junior high schools $[13,14]$. Thus overall, there is still a dearth of available programs targeted to meet the particular developmental needs of adolescents in this formative transition. 
In response to a scarcity of curricula to address middle school stress and depression, the Positive Thoughts and Actions (PTA) program was developed and tested for feasibility in the current pilot study. The PTA program falls under the spectrum of mental health interventions as an indicated school-based prevention, while schools that operate under a positive behavioral support framework would classify the PTA program as a selected/targeted intervention [15]. The middle/junior high school timeframe was chosen because it marks a time of change and transition when youth adapt to numerous psychological, physical, cognitive, and social changes that are associated with an increase in psychopathology [16-18]. Our PTA curriculum was designed to address depressive symptoms through intervention on three proximal intervention targets. These intervention targets-coping, cognitive style, and parent-child communication-were chosen as indicators of outcome based upon their theoretical links to risk for depression. Addressing some of the risk factors that contribute to the escalation of depressive symptoms at this age may be important in preventing long-term adjustment difficulties that can arise from subclinical depressive symptoms. This developmentally based prevention program is unique and innovative in addressing key factors that contribute to and perpetuate depressive symptoms during the early adolescent years.

First, evidence suggests that both youth and adults with depression have less adaptive and more limited coping repertoires compared to youth without depression $[19,20]$. For example, youth with depression may use less primary control (efforts to cope by making objective conditions conform to one's wishes) and secondary control (efforts to cope by adjusting oneself to fit objective conditions). Second, certain cognitive styles, including excessive negative thoughts and low levels of perceived control are characteristics unique to the development of depression $[21,22]$. Third, poor parentchild relationships and family communication difficulties serve as risk factors for the development of depression among youth [23].

Most tested intervention programs for adolescent depression, including those that are not school-based, have been delivered exclusively to the youth, without any parental involvement [23]. There are a number of reasons why the inclusion of parents in the intervention process may be particularly important for younger adolescents, including that reactions to difficult events or circumstances within the family can precipitate depressive symptoms, youth cannot change many aspects of their environment, and interventions can be more effective when they are implemented consistently across situations and persons. Providing psychoeducation to parents of depressed youth has been found to be beneficial by improving parents' coping skills and the family climate [24]. Moreover, several studies suggest that adolescents learn cognitive and coping styles from their parents and caregivers [25]. Thus far, only two other schoolbased depression prevention programs published in the literature have included an active parent component $[12,26]$.

This pilot trail of the PTA program was conducted to determine if the contextual focus of the PTA program was (1) acceptable to children and families, as indicated by their participation and satisfaction with intervention components, and (2) associated with improvements in youth's depressive symptoms, coping, cognitive style, and parent-child communication.

\section{Methods}

2.1. Subjects. A total of 677 th grade students were recruited from 4 Seattle Public Middle schools after school wide screening for depression was conducted on a larger sample $(n=684)$ in Fall of 2005 and Fall of 2006. Students who scored higher than 14 (top 25\%) on the Mood and Feelings Questionnaire (described below) after screening were invited to participate in the study. Exclusion criteria for students included (1) clinically elevated externalizing problems, (2) the presence of suicidal ideation, (3) probable diagnoses of Major Depressive Episode on the Patient Health Questionnaire-Adolescent Form, (4) plans to move to a nonparticipating school, and (5) parents who did not speak English. The first three exclusion categories were designed to ensure we were identifying youth who were appropriate for prevention and were not showing clinical levels of depression and related problem-behavior. Demographic characteristics of participating students and their families are provided in Table 1 . We were able to retain 58 of the original 67 students $(86.5 \%)$ for all followup assessments, as well as 60 of their parents $(89.5 \%)$.

\subsection{Instruments}

2.2.1. Mood and Feelings Questionnaire (MFQ). The MFQ was designed for children ranging in age from 8 to 18 and was written in parallel versions for parent and child, which both were administered in this study. The MFQ comprises both the full range of items assessing the DSM diagnostic criteria for depressive disorders as well as additional items reflecting common affective, cognitive, and vegetative aspects of childhood depression [27]. It has shown both high content validity and criterion validity [28]. Internal consistency (Cronbach's Alpha) was reported at .90 in both parent and child samples. Parent-report items predict psychiatric versus pediatric patient status and depressed versus nondepressed status in clinical groups. The MFQ correlates highly with depression diagnoses and the Child Depression Inventory [29]. For this study, internal consistency (Cronbach's alpha) ranged from .89 to .94 across the four time points.

2.2.2. Children's Depression Rating Scale-Revised (CDRS). The CDRS-R was administered to youth to assess the severity of depressive symptomatology. The CDRS-R is a clinicianrated scale used as a screening and diagnostic tool, consisting of 17 items scored from 1 to 5 or 1 to 7 [30]. The total score of the CDRS-R has been shown to be sensitive to change in severity of symptoms in treatment studies [31]. For this study, internal consistency (Cronbach alpha) ranged from .71 to .84 across the four time points. 
TABle 1: Demographic characteristics of participants.

\begin{tabular}{|c|c|c|c|c|}
\hline \multirow{2}{*}{$\begin{array}{l}\text { Characteristics } \\
\text { Mean Age (SD) }\end{array}$} & \multicolumn{2}{|c|}{ PTA group $n=36$} & \multicolumn{2}{|c|}{ Control group $n=31$} \\
\hline & 12.97 & $(0.36)$ & 13 & $(.40)$ \\
\hline \multicolumn{5}{|l|}{ Sex, $n(\%)$} \\
\hline Female & 20 & $(55.6)$ & 14 & $(45.2)$ \\
\hline Male & 16 & $(44.4)$ & 17 & $(54.8)$ \\
\hline \multicolumn{5}{|l|}{ Race, $n(\%)$} \\
\hline White & 24 & $(66.7)$ & 19 & $(61.3)$ \\
\hline African American & 1 & $(2.8)$ & 3 & $(9.7)$ \\
\hline Asian & 2 & $(5.6)$ & 3 & (9.7) \\
\hline Native American & 2 & $(5.6)$ & - & - \\
\hline Other & 7 & $(19.4)$ & 6 & $(19.4)$ \\
\hline \multicolumn{5}{|l|}{ Ethnicity, $n(\%)$} \\
\hline Hispanic & 1 & $(2.8)$ & 6 & (19.4) \\
\hline Non-Hispanic & 35 & $(97.2)$ & 25 & $(80.6)$ \\
\hline \multicolumn{5}{|l|}{ Parental Education, $n(\%)$} \\
\hline HS Diploma/GED/Some College & 13 & (36) & 12 & (39) \\
\hline Associates/Bachelor's Degree & 18 & (50) & 15 & (48) \\
\hline Masters/Professional/Doctoral Degree & 5 & (14) & 4 & (13) \\
\hline \multicolumn{5}{|l|}{ Family Constellation, $n(\%)$} \\
\hline Single (1 parent family) & 15 & $(42)$ & 9 & (29) \\
\hline Married (or 2 cohabitating parent) & 21 & (58) & 22 & (71) \\
\hline
\end{tabular}

2.2.3. Responses to Stress Questionnaire (RSQ). The RSQ [32] measures a range of responses to stress, including voluntary or controlled coping responses and involuntary or automatic reactions. Students are asked to rate how much they used specific coping techniques when faced with specific recent stressors. Scores from two scales were used for the current study: (1) primary control engagement coping (PCEC), encompassing problem solving, emotion regulation, and emotional expression, and (2) secondary control engagement coping (SCEC), encompassing positive thinking, cognitive restructuring, acceptance, and distraction. Convergent and discriminant validity of the RSQ has previously been established [33]. In the current sample, internal consistency (Cronbach alpha) for primary control coping ranged from .79 to .86 , and secondary control coping ranged from .68 to .84 .

2.2.4. Personal Control Scale. The personal control scale is a 5-item scale assessing the degree to which the youth feels a sense of control over their mood, problems, and life in general. It has previously shown good internal consistency ( $\alpha=.77)$ among high-school students [34]. For this study, internal consistency (Cronbach alpha) ranged from .82 to .85 .

2.2.5. Children's Automatic Thoughts Scale (CATS). CATS measures the frequency of negative thoughts, and has been validated on children aged 7-16 [35]. A 5-point rating scale ranging from 0 "not at all" to 4 "all the time" is used to rate 40 different automatic negative thoughts, including thoughts related to physical threat, social threat, personal failure, and hostility. Internal consistency of the subscales is high, with test-retest reliability adequate. In prior research, the CATS measure clearly discriminated clinically depressed youth from those with anxious and oppositional problems [35]. Internal consistency (Cronbach alpha) for this study was high, ranging from .91 to .96 .

2.2.6. Parent-Child Communication Scale (PCC). The PCC Scale includes both parent and child-report forms, and was adapted from the Revised Parent-Adolescent Communication Form of the Pittsburgh Youth Study [36, 37]. The child measure assesses children's perceptions of their primary caregiver's openness to communication (10 items), and the parent measure (20 items) assesses both parent and child communication skills. Other studies have reported alpha coefficients for communication subscales ranging from .66 to .81 in 7 th grade samples [38]. For this study, internal consistency (Cronbach alpha) for parent ratings of communication ranged from .51 to .81 across the four time points, whereas child ratings of communication ranged from .76 to .84 .

2.3. Procedures. All students who scored 14 or above on the MFQ were individually evaluated for clinical needs using a brief clinical evaluation protocol. Their parent or guardian was called and provided with feedback about the child's needs and referrals for resources, if indicated. Students and parents who met inclusion criteria and consented to participate were randomly assigned to the intervention group, Positive Thoughts and Actions (PTA) or the control group. 
TABle 2: Outline of the Positive Thoughts and Actions prevention program content.

(a)

\begin{tabular}{|c|c|c|}
\hline \multicolumn{3}{|r|}{ Student content } \\
\hline Session no. & Title & Content \\
\hline Week 1 & $\begin{array}{l}\text { Introduction and } \\
\text { Purpose }\end{array}$ & $\begin{array}{l}\text { To convey the purpose of the program, build a positive peer group, and to practice being positive } \\
\text { with others }\end{array}$ \\
\hline Week 2 & Setting Goals & $\begin{array}{l}\text { To motivate students to identify areas of their lives they would like to change and to select } \\
\text { targeted goals and specific steps to take within each program area }\end{array}$ \\
\hline Week 3 & Start with Action & To teach the importance of getting active to improve mood and persist in goals \\
\hline Week 4 & $\begin{array}{l}\text { Positive Thoughts, } \\
\text { Positive Feelings }\end{array}$ & To understand the link between thoughts and actions and to increase positive thinking \\
\hline Week 5 & $\begin{array}{l}\text { Changing the Way } \\
\text { We Think and Feel }\end{array}$ & To identify negative and irrational thoughts and change them to be more positive and realistic \\
\hline Week 6 & $\begin{array}{l}\text { STOP before } \\
\text { Responding }\end{array}$ & To help students recognize when they are having an emotional reaction and to regulate their affect \\
\hline Week 7 & $\begin{array}{l}\text { Making Decisions } \\
\text { \& Problem-Solving }\end{array}$ & To teach a 5-step approach to making decisions and solving problems \\
\hline Week 8 & $\begin{array}{l}\text { Managing Conflict } \\
\text { \& Anger }\end{array}$ & To help students manage moods by controlling anger and resolving conflicts more productively \\
\hline Week 9 & Learning & To apply the skills learned to identified school goals \\
\hline Week 10 & Relationships & To practice applying Positive Thoughts and Actions to relationships \\
\hline Week 11 & $\begin{array}{l}\text { Making Healthy } \\
\text { Decisions }\end{array}$ & To adopt more healthy behaviors \\
\hline Week 12 & $\begin{array}{l}\text { Staying on Track \& } \\
\text { Celebration }\end{array}$ & To recognize progress and identify areas of continued effort \\
\hline
\end{tabular}

(b)

\begin{tabular}{|c|c|c|}
\hline \multicolumn{3}{|r|}{ Parent content } \\
\hline Session type/no. & Title & Content \\
\hline Home Visit no. 1 & $\begin{array}{l}\text { Getting to Know } \\
\text { Each Other }\end{array}$ & To build rapport, to assess strengths and needs, and to help clarify the parents' supportive role \\
\hline $\begin{array}{l}\text { Parent Workshop } \\
\text { no. } 1\end{array}$ & $\begin{array}{l}\text { Positive Thoughts } \\
\text { \& Actions for } \\
\text { Parents }\end{array}$ & $\begin{array}{l}\text { To teach parents perspective-taking, and to provide an overview to the parent of emotion } \\
\text { regulation strategies }\end{array}$ \\
\hline $\begin{array}{l}\text { Parent Workshop } \\
\text { no. } 2\end{array}$ & $\begin{array}{l}\text { Communicating } \\
\text { with Your Teen }\end{array}$ & $\begin{array}{l}\text { To give parents an opportunity to learn and practice different ways to communicate about } \\
\text { feelings and/or problems }\end{array}$ \\
\hline Home Visit no. 2 & Staying Successful & $\begin{array}{l}\text { To provide an opportunity for the student to summarize key concepts and identify how the } \\
\text { parent can support them }\end{array}$ \\
\hline
\end{tabular}

PTA took place at school, consisting of 12 weekly (once per week) group-administered sessions, two home visits with parents and student together, and two groupbased parent workshops, conducted in the evenings at the students' school. The PTA program included aspects of behavioral, cognitive, interpersonal, and family-systems interventions, the content of which is detailed in Table 2. PTA taught three major skills: thinking positively, taking positive action, and problem solving. Students applied these skills to self-identified problems/goals, and parents were given communication and problem-solving tools to help support their children.

The control group participants received usual care in the school, meaning they were free to seek school-based (e.g., counseling) or other services (e.g., community mental health), but they were not provided with systematic intervention. Control group students attended their regular academic classes during the PTA student group time. Thirtyone students were assigned to the control group and 36 to the PTA intervention group.

Trained graduate level interviewers conducted structured research interviews in the family home. All instruments were administered to students and parents by separate interviewers after explaining the instructions and answering their questions. Participants were interviewed using all study measures at four time points: Winter of 7 th grade, prior to the start of intervention (Baseline), Spring of 7 th grade, in the weeks following intervention (Postintervention), Winter 
of 8th grade, (6-months followup), and Fall/Winter of 9th grade, (18-months followup).

2.4. Data Analysis. Descriptive statistics were used to summarize demographic data. To determine the effects of the intervention, general linear model (GLM) repeatedmeasures analyses were conducted for each dependent variable with group (PTA versus control group) as the between-subjects variable and time as the within-subject variable. All analyses were conducted controlling for baseline levels depressive symptoms (CDRS). When significant time or group effects were found, posthoc contrasts were analyzed to determine the source of the individual differences. The statistical package used to run all analyses was SPSS (version 17.0), with statistical significance set at $P<.05$. Effect sizes (ESs) were also computed for all variables in order to examine the magnitude and direction of effects, using the procedures for Cohen's d with adjusted means (difference between the adjusted means of the treatment and control group, divided by a pooled standard deviation) [39]. All ESs were calculated such that positive values implied an advantage for intervention over control group.

\section{Results}

3.1. Participation and Satisfaction. Of the students randomized to the intervention group, 35 of 36 completed the prevention program, with an average attendance rate of 11 of 12 sessions for completers. One hundred percent of the parents of PTA youth received at least some of the parent intervention, and $94 \%$ received at least three of the four sessions. Twenty-six of the parent participants were mothers only $(72 \%), 6$ were fathers only (17\%), 3 families had both parents participate $(8 \%)$, and 1 "other caregiver" was the primary respondent $(3 \%)$.

Parent satisfaction ratings were obtained following the initial parent-child home visit and the parent workshops. Of the 36 PTA parents, $72 \%$ of the parents found the initial home visit to be "very helpful", $25 \%$ found it to be "somewhat helpful", while one parent found the session to be "a little helpful". Overall, the parent workshop components were rated to be "very helpful" (45\%) or "somewhat helpful" $(55 \%)$ by those who participated.

Student satisfaction with their group membership and feelings about PTA class were gathered at week 11 of the intervention. Of the 36 PTA students, $48 \%$ liked the group they were in "very much", $36 \%$ liked the group "pretty much", and $13 \%$ felt the group was "all right". One student (3\%) disliked the group a little and felt "embarrassed" about being in the class. Twenty percent reported feeling neutral about being in the class. The remaining students felt "comfortable" $(30 \%)$ or "very comfortable" (47\%) about being in the class.

3.2. Depressive Outcomes. Total scores on the Children's Depression Rating Scale-Revised showed a significant main effect across time $F_{2,53}=4.89, P=.01$. Followup analyses revealed CDRS-R scores varied for the control group only
$\left(F_{2,20}=8.67, P=.002\right)$ with higher CDRS-R scores at postintervention and 18-month followup compared to 6-month followup. No significant interaction effect between time $x$ group $\left(F_{2,53}=.73, P=.49\right)$ was found. Overall, parents reported fewer depressive symptoms than youth, as shown in Table 4. Parent ratings of depressive symptoms (MFQP) varied significantly across time, $F_{3,49}=4.10, P=.01$. Parents in the control group reported significantly fewer depressive symptoms at 6-month and 18-month followup than baseline, $F_{3,18}=3.62, P=.03$. For parents in the intervention group, ratings of their child's depression were lower at 6-month followup compared to baseline $(P=.03)$, though overall mean differences were nonsignificant, $F_{3,28}=1.71, P=.19$. No significant effects were found for depressive symptoms on the child-report MFQ $(P=.95)$.

Examination of effect sizes for depression outcomes yielded a mixed picture, depending on time and informant (see Table 5). Youth PTA participants reported slightly higher mean levels of depressive symptoms after the intervention, compared to control youth, as indicated by the negative effect size value (ES $=-.16$ ). By 18 month followup, when participants were in the 9th grade, the pattern of results reversed, showing a slight advantage for PTA participants (ES $=.18$ ). Effect sizes based upon parental report suggested that parents of youth in the intervention group reported more depressive symptoms among their children at postintervention and 18-month followup. The CDRS yielded neutral to medium negative effect size values, although the two groups were not well matched in their CDRS scores at baseline.

3.3. Coping, Cognitive Style, and Parent-Child Communication. As for the three proximal intervention targets, primary control coping showed a significant main effect for group, $F_{1,53}=7.22, P=.01$. PTA participants were found to have significantly higher mean levels of primary control engagement coping than the control group. Follow-up repeated-measures for group showed the PTA participants demonstrated significant improvements in coping at post-intervention compared to baseline $\left(F_{3,29}=7.43, P=.01\right)$. No significant interaction effect between time $\mathrm{x}$ group for primary coping (PCEC) were found $(P=.86)$, nor were differences in secondary coping (SCEC) on the RSQ significant $(P=.20)$. In terms of our two measures of cognition, differences across time and group were found for one of these outcomes. Personal control scale showed a significant time $\mathrm{x}$ group interaction, $F_{3,52}$ $=3.61, P=.02$. Followup analyses revealed differences for both groups, with mean differences shown in Table 3. PTA participants had significantly higher mean levels of perceived control at 18 -month follow-up compared to baseline $\left(F_{3,30}\right.$ $=2.92, P=.05)$, while control group youth had significantly higher mean levels at 6-month follow up compared to postintervention $\left(F_{3,19}=3.70, P=.03\right)$. No significant effects between groups were found for automatic negative thoughts $(P=.92)$, though effect sizes suggested small advantages for the treatment group over all time points (see Table 4).

Finally, for parent-child communication, no significant differences were found for communication on the PCC parent or child versions, $P=.61$ and $P=.31$, respectively. 
TABLE 3: Adjusted mean scores on depressive measures by group and time.

\begin{tabular}{|c|c|c|c|}
\hline \multirow{2}{*}{$\begin{array}{l}\text { Construct } \\
\text { Measure }\end{array}$} & \multicolumn{3}{|c|}{ Depressive Symptoms } \\
\hline & MFQ-C & MFQ-P & CDRS \\
\hline \multicolumn{4}{|l|}{ PTA } \\
\hline Baseline & $14.42(9.85)$ & $10.51(10.17)$ & $26.17(7.50)$ \\
\hline Post-intervention & $15.91(10.24)$ & $9.11(11.27)$ & $27.45(7.43)$ \\
\hline 6-month followup & $10.86(10.59)$ & $7.37(7.64)$ & $25.67(7.77)$ \\
\hline 18-month followup & $16.17(10.83)$ & $9.28(8.42)$ & $27.75(9.04)$ \\
\hline \multicolumn{4}{|l|}{ Controls } \\
\hline Baseline & $14.87(10.41)$ & $10.67(7.22)$ & $23.95(6.17)$ \\
\hline Post-intervention & $14.50(7.41)$ & $8.05(6.44)$ & $27.30(6.78)$ \\
\hline 6-month followup & $11.67(6.83)$ & $7.57(5.65)$ & $22.96(4.01)$ \\
\hline 18-month followup & $18.10(10.96)$ & $6.01(5.26)$ & $27.01(9.61)$ \\
\hline
\end{tabular}

Standard deviations are in parentheses. MFQ-C: Mood and Feelings Questionnaire-Child; MFQ-P: Mood and Feelings Questionnaire-Parent; CDRS: Children's Depression Rating Scale.

TABle 4: Effect sizes (Cohen's D) for outcomes across time.

\begin{tabular}{|c|c|c|c|c|c|c|c|c|c|}
\hline \multirow{2}{*}{$\begin{array}{l}\text { Construct } \\
\text { Measure }\end{array}$} & \multicolumn{2}{|c|}{ Coping } & \multicolumn{2}{|c|}{ Cognition } & \multicolumn{2}{|c|}{ Parent-child communication } & \multicolumn{3}{|c|}{ Depressive symptoms } \\
\hline & PCEC & SCEC & $\mathrm{PC}$ & CATS & PCCC & PCCP & MFQ-C & MFQ-P & CDRS \\
\hline \multicolumn{10}{|c|}{ Postintervention } \\
\hline & .67 & .51 & .64 & .17 & .35 & .39 & -.16 & -.12 & -.02 \\
\hline \multicolumn{10}{|c|}{ 6-month followup } \\
\hline & .52 & -.05 & -.32 & .2 & -.04 & .15 & .09 & .03 & -.44 \\
\hline \multicolumn{10}{|c|}{ 18-month followup } \\
\hline & .5 & .16 & .2 & .24 & .04 & -.01 & .18 & -.47 & -.08 \\
\hline
\end{tabular}

Effect sizes were calculated using adjusted means from GLM (reported in Table 3).

$(+)=$ Treatment $>$ Control (better than); $(-)=$ Treatment $<$ Control (worse than).

Effect sizes suggested that both parent and youth participants in the intervention condition reported better parentchild communication following intervention, but that these improvements relative to the control group did not sustain over time.

\section{Discussion}

The Positive Thoughts and Actions prevention program was well received by students and parents, yielding high rates of participation and satisfaction among those randomized to receive the intervention. Nearly $84 \%$ of adolescent participants reported liking the group. While indicated prevention programs that target individuals who display some early signs or symptoms have been criticized for the potential for increased labeling and stigma, we found that students' perceived embarrassment as a result of participation was low, with 77\% reporting feeling "comfortable" or "very comfortable" participating, and another 20\% reporting "neutral" feelings. These low levels of stigma are consistent with those reported among participants another schoolbased depression prevention, the Adolescents Coping with Emotions program [40]. Overall, the program was acceptable to students and families, and the structure of the intervention was conducive to participation. The conceptual framework for the program, intervention targets, and inclusion of developmentally salient applications, such as learning, relationships, and making healthy decisions, were well received by our partner schools.

Analyses of the efficacy of the PTA program relative to the control group in changing depressive symptoms were not significant. Effect-size patterns were inconsistent across time and informant, with some negative effect-size values which could indicate iatrogenic effects of the PTA group. However, given the degree of scatter in mean values for youth-report measures, the fact that the PTA participants had higher CDRS scores at baseline, and the decrease in parent-reported depressive symptoms across time for both groups, it is difficult to discern the overall impact of PTA with these data. Moreover, effect size estimates using small sample sizes are prone to bias [41], and this can be further exacerbated when measuring episodic phenomena such as depressive symptoms. The PTA program developers are currently revising program materials based on input from consumers and two depression prevention expert consultants, and will conduct a larger trial as a next step. Increased sample size and power will allow for stronger conclusions about intervention effects to be made, but does not replace the importance of publishing these pilot data [42].

In terms of our proximal program targets, effect sizes suggested an advantage of the PTA over control group in each area, though most differences (aside from primary control 
TABLE 5: Adjusted mean scores on proximal outcome measures by group and time.

\begin{tabular}{|c|c|c|c|c|c|c|}
\hline \multirow{2}{*}{$\begin{array}{l}\text { Construct } \\
\text { Measure }\end{array}$} & \multicolumn{2}{|c|}{ Coping } & \multicolumn{2}{|c|}{ Cognition } & \multicolumn{2}{|c|}{ Parent-Child Communication } \\
\hline & PCEC & SCEC & $\mathrm{PC}$ & CATS & PCCC & PCCP \\
\hline \multicolumn{7}{|l|}{ PTA } \\
\hline Baseline & $25.88(4.37)$ & $30.93(4.97)$ & $20.78(5.65)$ & $25.06(18.75)$ & $19.93(3.15)$ & $25.56(3.28)$ \\
\hline Postintervention & $26.15(5.74)$ & $32.42(7.54)$ & $21.79(5.39)$ & $19.92(14.84)$ & $19.29(4.61)$ & $25.64(2.86)$ \\
\hline 6-month followup & $26.04(5.14)$ & $21.61(6.03)$ & $21.61(6.03)$ & $19.61(19.55)$ & $19.60(2.77)$ & $25.24(2.90)$ \\
\hline 18-month followup & $26.10(6.17)$ & $22.93(5.22)$ & $22.93(5.22)$ & $19.67(19.84)$ & $19.31(3.93)$ & $24.58(3.73)$ \\
\hline \multicolumn{7}{|l|}{ Controls } \\
\hline Baseline & $22.81(5.17)$ & $30.06(6.43)$ & $19.63(6.13)$ & $26.15(20.68)$ & $19.76(4.07)$ & $24.93(3.61)$ \\
\hline Post-intervention & $22.48(5.23)$ & $28.85(6.33)$ & $18.27(5.59)$ & $22.55(15.92)$ & $17.83(3.56)$ & $24.51(2.88)$ \\
\hline 6-month followup & $23.42(5.03)$ & $23.31(4.48)$ & $23.31(4.48)$ & $23.77(22.06)$ & $19.72(3.35)$ & $24.80(3.04)$ \\
\hline 18-month followup & $23.61(3.28)$ & $21.89(5.08)$ & $21.89(5.08)$ & $24.48(19.06)$ & $19.15(4.24)$ & $24.62(3.75)$ \\
\hline
\end{tabular}

Standard deviations are in parentheses. PCEC: Primary Control Engagement Coping; SCEC: Secondary Control Engagement Coping; PC: Personal Control; CATS: Children's Automatic Thoughts Questionnaire; PCCC: Parent Child Communication-Child; PCCP: Parent Child Communication—Parent.

engagement coping) were not large enough to achieve statistical significance. The largest and most robust increases for PTA participants were in areas of personal control and primary control engagement coping over time. Personal control and coping are common targets of preventative programs targeted to youth with internalizing problems, such as depression or suicidal ideation [34]. Gains in self-efficacy and control are associated with decreased vulnerability to suicide $[43,44]$ and moreover these skills are potentially important in and of themselves because they confer a sense of autonomy and increased personal resources for handling stress. Knowledge of coping skills can reduce and prevent negative consequences of stress in adolescence, thereby having far-reaching benefits that extend beyond a specific disorder. Resiliency research has linked positive adjustment to successful coping with developmental challenges. In terms of magnitude, differences in primary control engagement coping between PTA and control groups were "medium" in size.

However, it is important to note that despite these changes in primary control engagement coping, none of the changes in depressive symptoms were significant over time for PTA participants, showing a disconnect between outcomes. While we had conceptualized coping, cognitive style, and parent-child communication to be potential mechanisms for change in depressive symptoms, our results were not consistent with a meditational model because mediation is predicated on observing a clear intervention effect. Few other studies have examined mechanisms of change in depression intervention [45], and those that have tested for mediation have not found evidence that cognition necessarily mediates outcome in CBT outcome [46].

PTA stands out as one of the first programs to successfully implement a school-based intervention focused on depression with high levels of parent engagement. We were able to successfully engage at least one parent from all families through our outreach efforts to meet with them at their home or another convenient location. Meetings were scheduled in the evenings or on the weekends, at a time that worked best for the family. The same intervention specialist who would be leading student groups set up a meeting with the family prior to the first group. Surveys of parent availability were conducted prior to scheduling all parent workshops to maximize attendance. Intervention specialists made personalized reminder calls prior to each workshop and family meeting to engage parents. In the final student group, students practiced giving a short speech about what they gained from the experience. Then, in the final family session, students presented this synopsis to their parent(s), as well as demonstrating some of the concepts learned from the PTA curriculum. All in all, the close tie between student groups and the parent component was believed to help foster parents' engagement and interest in participating.

This participation rate is higher than that found by other depression prevention programs based in schools. For example, in the Australian test of the resourceful adolescent program (RAP), only $36 \%$ of adolescents had a parent attend any session and 10\% attended all 3 sessions. Our rates of parent participation in any intervention were similar to those achieved by the Penn Resiliency Program (PRP), where parents of $91 \%$ of students attended at least one of the parent intervention component sessions. However, our study yielded a much larger uptake when considering the percentage of parents participating in the majority of the intervention, with $94 \%$ of our parents completing at least three of the four parent sessions. The PRP parent intervention consisted of six 90-minute sessions targeted to parents' cognitions and coping skills, with $41 \%$ of parents attending at least five of the six sessions [26]. Thus, the results of our study, conducted in urban Seattle, and those of the PRP, conducted in suburban Pennsylvania, together demonstrate that it is possible to achieve high rates of parental involvement for school-based prevention programs when adequate resources for outreach are provided, such as meeting with parents at their home and at their convenience.

\section{Conclusion}

Schools are faced with increasing pressure to address the emotional wellbeing of students to promote learning and 
healthy development. Building programs to address mental health is a critical component to improving overall school health. This preliminary research highlights the feasibility of school-based prevention programs addressing depression and promotion of positive emotional health. The most significant limitation of this research is the small sample size that was used in this feasibility trial. While it is difficult to draw conclusions about the outcome of the intervention given the small sample size, the intervention was well received, and parents were particularly engaged. However, it possible that identification and attention alone contributed to parent and student satisfaction, and both conditions were provided with a brief clinical evaluation and feedback, which may have had some effect on outcomes. Study information contributes to the meager understanding of the feasibility and uptake of school-based preventative interventions addressing depressive symptoms during middle/junior high school, and lays the foundation for further research examining the effectiveness and value of such programs for consumers, including students, parents, and school personnel. Future examination of the PTA program in additional schools with a larger sample will determine the effectiveness as a depression prevention curriculum.

\section{Human Subjects Approval Statement}

All study procedures were approved by the University of Washington Institutional Review Board.

\section{Acknowledgments}

This research was supported by Grant no. K01 MH69892 from the National Institute of Mental Health (awarded to C. McCarty) and was previously presented at the Society for Prevention Research (May, 2008). The authors wish to thank the participating students and parents and their school partners in the Seattle Public Schools for their willingness to collaborate and their valuable contributions to the authors research program.

\section{References}

[1] C. Hammen and K. D. Rudolph, "Childhood depression," in Child Psychopathology, E. J. Mash and R. A. Barkley, Eds., Guilford Press, New York, NY, USA, 1996.

[2] I. H. Gotlib, P. M. Lewinsohn, and J. R. Seeley, "Symptoms versus a diagnosis of depression: differences in psychosocial functioning," Journal of Consulting and Clinical Psychology, vol. 63, no. 1, pp. 90-100, 1995.

[3] D. S. Pine, E. Cohen, P. Cohen, and J. Brook, "Adolescent depressive symptoms as predictors of adult depression: moodiness or mood disorder?" American Journal of Psychiatry, vol. 156, no. 1, pp. 133-135, 1999.

[4] D. M. Fergusson, L. J. Horwood, E. M. Ridder, and A. L. Beautrais, "Suicidal behaviour in adolescence and subsequent mental health outcomes in young adulthood," Psychological Medicine, vol. 35, no. 7, pp. 983-993, 2005.

[5] E. J. Costello, D. S. Pine, C. Hammen et al., "Development and natural history of mood disorders," Biological Psychiatry, vol. 52, no. 6, pp. 529-542, 2002.
[6] M. M. Weissman, S. Wolk, R. B. Goldstein et al., "Depressed adolescents grown up," Journal of the American Medical Association, vol. 281, no. 18, pp. 1707-1713, 1999.

[7] The National Academies, Preventing Mental, Emotional, and Behavioral Disorders Among Young People: Progress and Possibilities, Washington, DC, USA, 2009.

[8] M. Rones and K. Hoagwood, "School-based mental health services: a research review," Clinical Child and Family Psychology Review, vol. 3, no. 3, pp. 223-241, 2000.

[9] B. J. Burns, E. J. Costello, A. Angold et al., "Children's mental health service use across service sectors," Health Affairs, vol. 14, no. 3, pp. 147-159, 1995.

[10] S. H. Spence, J. Sheffield, and C. Donovan, "Problem-solving orientation and attributional style: moderators of the impact of negative life events on the development of depressive symptoms in adolescence?" Journal of Clinical Child and Adolescent Psychology, vol. 31, no. 2, pp. 219-229, 2002.

[11] D. Quayle, S. Dziurawiec, C. Roberts, R. Kane, and G. Ebsworthy, "The effect of an optimism and lifeskills program on depressive symptoms in preadolescence," Behaviour Change, vol. 18, no. 4, pp. 194-203, 2001.

[12] I. M. Shochet, M. R. Dadds, D. Holland, K. Whitefield, P. H. Harnett, and S. M. Osgarby, "The efficacy of a universal school-based program to prevent adolescent depression," Journal of Clinical Child and Adolescent Psychology, vol. 30, no. 3, pp. 303-315, 2001.

[13] J. E. Gillham, K. J. Reivich, L. H. Jaycox, and M. E. P. Seligman, "Prevention of depressive symptoms in schoolchildren: twoyear follow-up," Psychological Science, vol. 6, no. 6, pp. 343$351,1995$.

[14] D. R. Freres, J. E. Gillham, K. Reivich, and A. J. Shatté, "Preventing depressive symptoms in middle school students: the Penn Resiliency Program," International Journal of Emergency Mental Health, vol. 4, no. 1, pp. 31-40, 2002.

[15] R. H. Horner, R. W. Albin, J. R. Sprague, and A. W. Todd, "Positive behavior support for students with severe disabilities," in Instruction of Students with Severe Disabilities, M. E. Snell and F. Brown, Eds., pp. 207-243, Merill/PrenticeHall, Upper Saddle River, NJ, USA, 1999.

[16] A. C. Petersen and B. A. Hamburg, "Adolescence: a developmental approach to problems and psychopathology," Behavior Therapy, vol. 17, no. 5, pp. 480-499, 1986.

[17] Carnegie Council on Adolescent Development, Turning Points: Preparing American Youth for the 21st Century, Washington, DC, USA, 1989.

[18] J. Brooks-Gunn and E. O. Reiter, "The role of pubertal processes," in At the Threshold: The Developing Adolescent, S. S. Feldman and G. R. Elliott, Eds., Harvard University Press, Cambridge, Mass, USA, 1990.

[19] N. Garnefski, J. Legerstee, V. Kraaij, T. Van Den Kommer, and J. Teerds, "Cognitive coping strategies and symptoms of depression and anxiety: a comparison between adolescents and adults," Journal of Adolescence, vol. 25, no. 6, pp. 603-611, 2002.

[20] R. D. Goodwin, "Association between coping with anger and feelings of depression among youths," American Journal of Public Health, vol. 96, no. 4, pp. 664-669, 2006.

[21] J. R. Weisz, M. A. Southam-Gerow, and C. A. McCarty, "Control-related beliefs and depressive symptoms in clinicreferred children and adolescents: developmental differences and model specificity," Journal of Abnormal Psychology, vol. 110, no. 1, pp. 97-109, 2001.

[22] C. A. McCarty, W. A. Mason, R. Kosterman, J. D. Hawkins, L. J. Lengua, and E. McCauley, "Adolescent school failure predicts 
later depression among girls," Journal of Adolescent Health, vol. 43, no. 2, pp. 180-187, 2008.

[23] J. B. Sander and C. A. McCarty, "Youth depression in the family context: familial risk factors and models of treatment," Clinical Child and Family Psychology Review, vol. 8, no. 3, pp. 203-219, 2005.

[24] M. A. Fristad, S. M. Gavazzi, and K. W. Soldano, "Multifamily psychoeducation groups for childhood mood disorders: a program description and preliminary efficacy data," Contemporary Family Therapy, vol. 20, no. 3, pp. 385-402, 1998.

[25] J. Garber and C. Flynn, "Predictors of depressive cognitions in young adolescents," Cognitive Therapy and Research, vol. 25, no. 4, pp. 353-376, 2001.

[26] J. E. Gillham, K. J. Reivich, D. R. Freres et al., "Schoolbased prevention of depression and anxiety symptoms in early adolescence: a pilot of a parent intervention component," School Psychology Quarterly, vol. 21, no. 3, pp. 323-348, 2006.

[27] E. J. Costello and A. Angold, "Scales to assess child and adolescent depression: checklists, screens, and nets," Journal of the American Academy of Child and Adolescent Psychiatry, vol. 27, no. 6, pp. 726-737, 1988.

[28] A. Angold, E. J. Costello, S. C. Messer, and A. Pickles, "Development of a short questionnaire for use in epidemiological studies of depression in children and adolescents," International Journal of Methods in Psychiatric Research, vol. 5, no. 4, pp. 237-249, 1995.

[29] M. Kovacs, The Children's Depression Inventory Manual, MultiHealth Systems, North Tonawanda, NY, USA, 1992.

[30] E. O. Poznanski and H. Mokros, Children's Depression Rating Scale (CDRS-R), Western Psychological Services, Los Angeles, Calif, USA, 1996.

[31] G. J. Emslie, A. John Rush, W. A. Weinberg et al., "A doubleblind, randomized, placebo-controlled trial of fluoxetine in children and adolescents with depression," Archives of General Psychiatry, vol. 54, no. 11, pp. 1031-1037, 1997.

[32] J. K. Connor-Smith, B. E. Compas, M. E. Wadsworth, A. H. Thomsen, and H. Saltzman, "Responses to stress in adolescence: measurement of coping and involuntary stress responses," Journal of Consulting and Clinical Psychology, vol. 68, no. 6, pp. 976-992, 2000.

[33] C. S. Carver, M. F. Scheier, and K. J. Weintraub, "Assessing coping strategies: a theoretically based approach," Journal of Personality and Social Psychology, vol. 56, no. 2, pp. 267-283, 1989.

[34] B. P. Randell, L. L. Eggert, and K. C. Pike, "Immediate post intervention effects of two brief youth suicide prevention interventions," Suicide and Life-Threatening Behavior, vol. 31, no. 1, pp. 41-61, 2001.

[35] C. A. Schniering and R. M. Rapee, "Development and validation of a measure of children's automatic thoughts: the children's automatic thoughts scale," Behaviour Research and Therapy, vol. 40, no. 9, pp. 1091-1109, 2002.

[36] R. Loeber, D. P. Farrington, M. Stouthamer-Loeber, and W. B. Van Kammen, Antisocial Behavior and Mental Health Problems: Explanatory Factors in Childhood and Adolescence, Lawrence Erlbaum Associates, Mahwah, NJ, USA, 1988.

[37] T. P. Thornberry, D. Huizinga, and R. Loeber, "The prevention of serious delinquency and violence: implications from the program of research on the causes and correlates of delinquency," in Sourcebook on Serious, Violent, and Chronic Juvenile Offenders, J. C. Howell, B. Krisberg, J. D. Hawkins, et al., Eds., pp. 213-327, Sage, Thousand Oaks, Calif, USA, 1995.
[38] C. A. McCarty and S. R Doyle, "Parent-child communication, child report," Tech. Rep., 2001, http://sanford.duke.edu/ centers/child/fasttrack/techrept/p/pcc/.

[39] J. Cohen, Statistical Power Analysis for the Behavioral Sciences, Erlbaum, Hillsdale, NJ, USA, 2nd edition, 1988.

[40] R. M. Rapee, A. Wignall, J. Sheffield et al., "Adolescents' reactions to universal and indicated prevention programs for depression: perceived stigma and consumer satisfaction," Prevention Science, vol. 7, no. 2, pp. 167-177, 2006.

[41] H. C. Kraemer, J. Mintz, A. Noda, J. Tinklenberg, and J. A. Yesavage, "Caution regarding the use of pilot studies to guide power calculations for study proposals," Archives of General Psychiatry, vol. 63, no. 5, pp. 484-489, 2006.

[42] N. Feeley, S. Cossette, J. Cote, et al., "The importance of piloting an RCT intervention," Canadian Journal of Nursing Research, vol. 41, no. 2, pp. 85-99, 2009.

[43] P. M. Lewinsohn, P. Rohde, and J. R. Seeley, "Psychosocial risk factors for future adolescent suicide attempts," Journal of Consulting and Clinical Psychology, vol. 62, no. 2, pp. 297-305, 1994.

[44] E. A. Thompson, K. A. Moody, and L. L. Eggert, "Discriminating suicide ideation among high-risk youth," The Journal of school health, vol. 64, no. 9, pp. 361-367, 1994.

[45] V. R. Weersing and J. R. Weisz, "Mechanisms of action in youth psychotherapy," Journal of Child Psychology and Psychiatry and Allied Disciplines, vol. 43, no. 1, pp. 3-29, 2002.

[46] D. J. Kolko, D. A. Brent, M. Baugher, J. Bridge, and B. Birmaher, "Cognitive and family therapies for adolescent depression: treatment specificity, mediation, and moderation," Journal of Consulting and Clinical Psychology, vol. 68, no. 4, pp. 603-614, 2000 . 


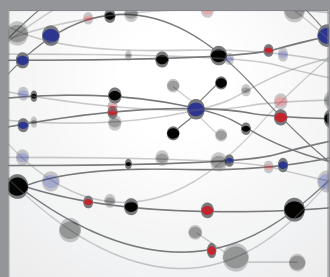

The Scientific World Journal
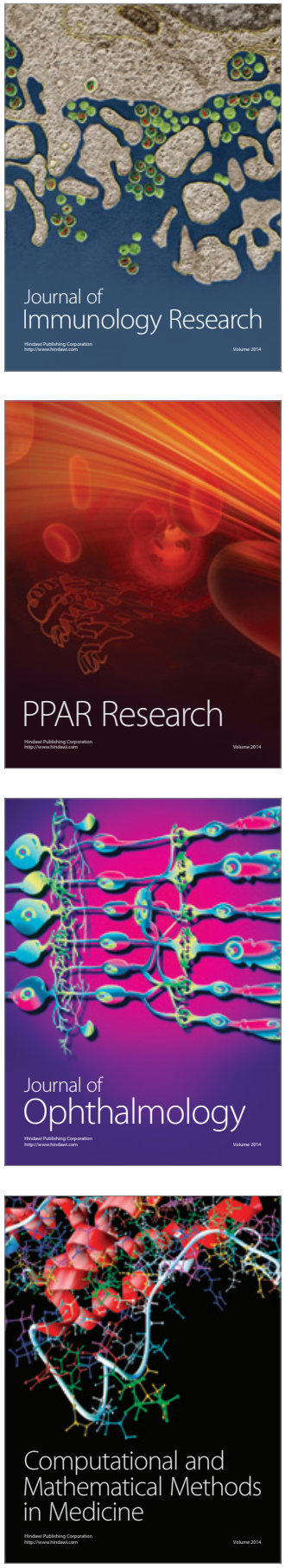

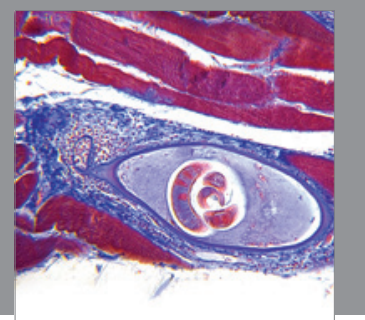

Gastroenterology

Research and Practice
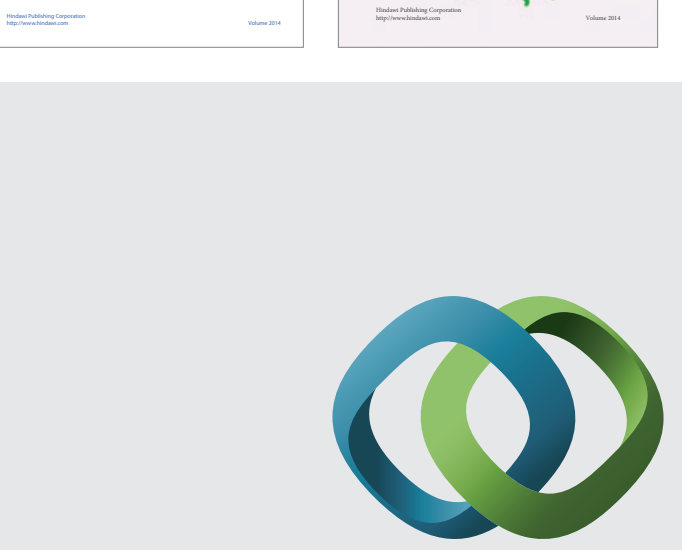

\section{Hindawi}

Submit your manuscripts at

http://www.hindawi.com
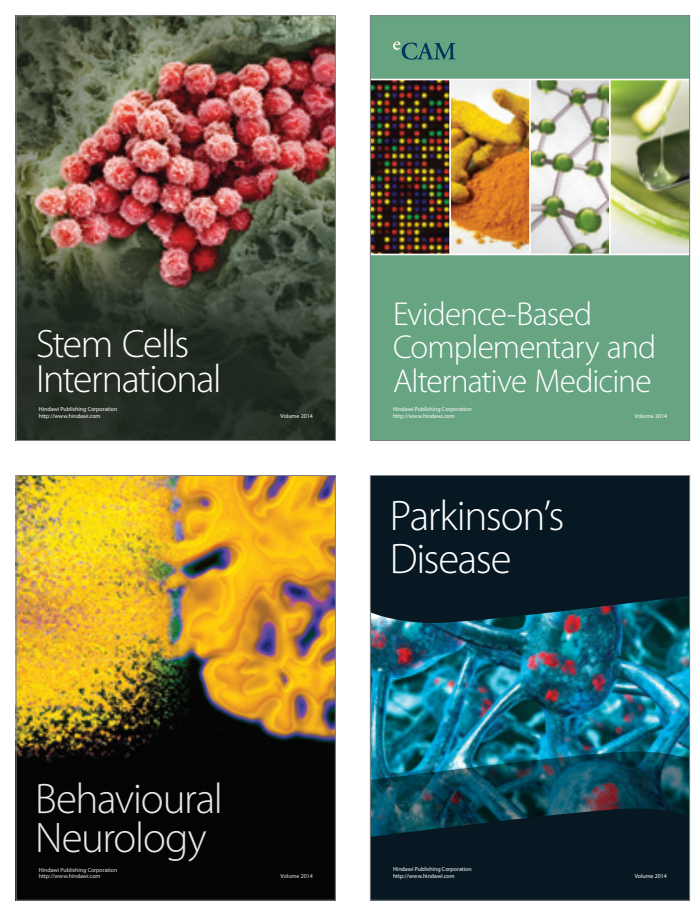

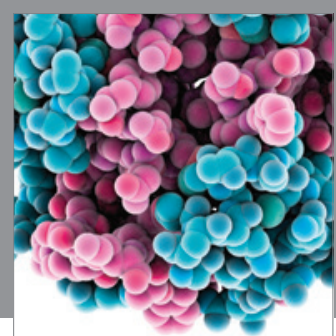

Journal of
Diabetes Research

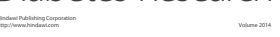

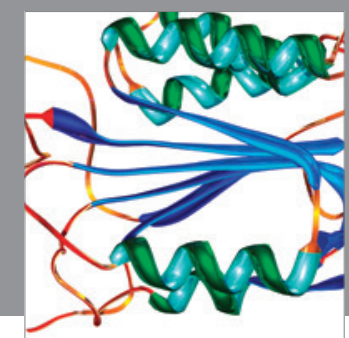

Disease Markers
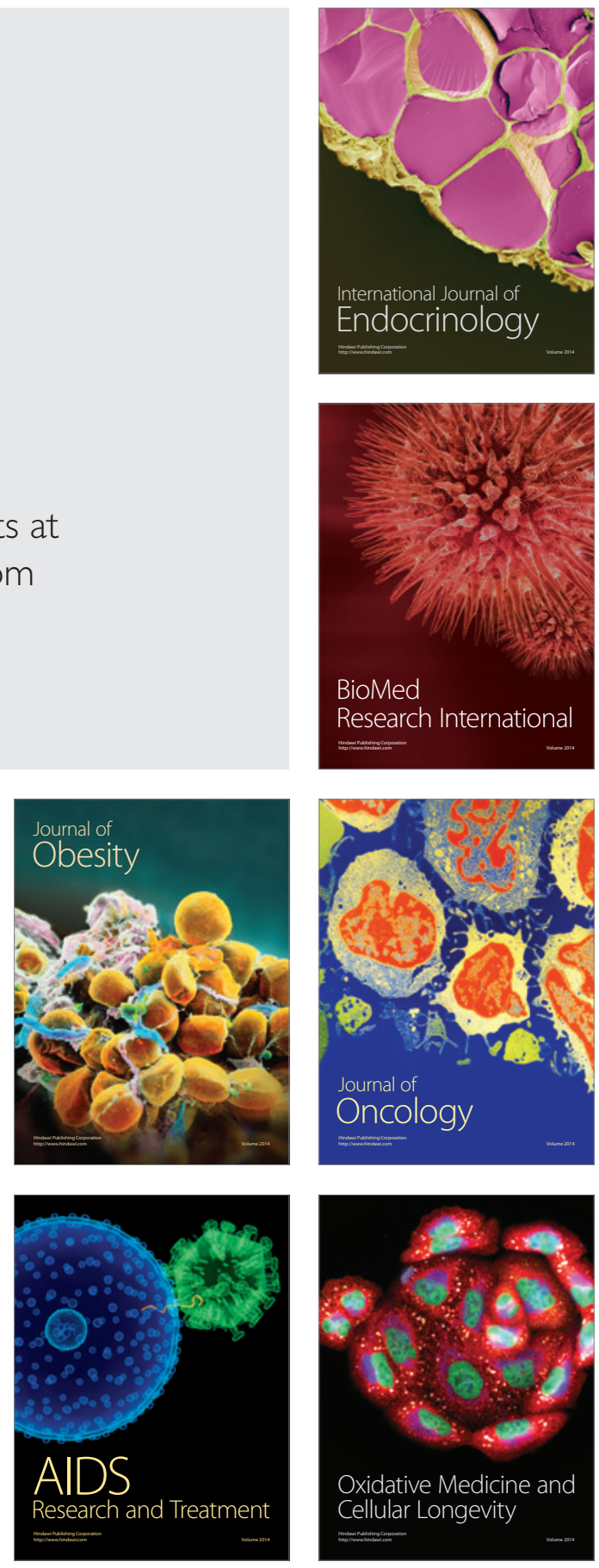